BMJ Open Diabetes Research \& Care

\title{
Glycemic responses to strenuous training in male professional cyclists with type 1 diabetes: a prospective observational study
}

Olivia McCarthy (D) , ${ }^{1,2}$ Max L Eckstein, ${ }^{3}$ Sam N Scott (D) , ${ }^{4}$ Federico Y Fontana,,${ }^{5,6}$ Mark P Christiansen, ${ }^{7}$ Christoph Stettler (D) , ${ }^{8}$ Miles Fisher, ${ }^{9}$ Bruce Bode, ${ }^{10}$ Michael C Riddell, ${ }^{11}$ Charlotte Hayes, ${ }^{6}$ Peter L Lagrou, ${ }^{12}$ Phil Southerland, ${ }^{6}$ Othmar Moser (D) , ${ }^{3}$ Richard M Bracken ${ }^{1,2}$

To cite: McCarthy 0 , Eckstein ML, Scott SN, et al. Glycemic responses to strenuous training in male professional cyclists with type 1 diabetes: a prospective observational study. BMJ Open Diab Res Care 2020;8:e001245. doi:10.1136/ bmjdrc-2020-001245

- Additional material is published online only. To view please visit the journal online (http://dx.doi.org/10.1136/ bmjdrc-2020-001245).

Received 7 February 2020 Revised 12 March 2020 Accepted 24 March 2020
Check for updates

(C) Author(s) (or their employer(s)) 2020. Re-use permitted under CC BY-NC. No commercial re-use. See rights and permissions. Published by BMJ.

For numbered affiliations see end of article.

Correspondence to Dr Olivia McCarthy; olivia.mccarthy@swansea. ac.uk

\section{ABSTRACT}

Introduction This prospective observational study sought to establish the glycemic, physiological and dietary demands of strenuous exercise training as part of a 9-day performance camp in a professional cycling team with type 1 diabetes (T1D).

Research design and methods Sixteen male professional cyclists with T1D on multiple daily injections (age: $27 \pm 4$ years; duration of T1D: $11 \pm 5$ years; body mass index: $22 \pm 2 \mathrm{~kg} / \mathrm{m}^{2}$; glycated hemoglobin: $7 \% \pm 1 \%$ ( $50 \pm 6 \mathrm{mmol} / \mathrm{mol})$; maximum rate of oxygen consumption: $73 \pm 4 \mathrm{~mL} / \mathrm{kg} / \mathrm{min})$ performed road cycle sessions $(50 \%$ $90 \%$ of the anaerobic threshold, duration 1-6hours) over 9 consecutive days. Glycemic (Dexcom G6), nutrition and physiological data were collected throughout. Glycemic data were stratified into predefined glycemic ranges and mapped alongside exercise physiology and nutritional parameters, as well as split into daytime and night-time phases for comparative analysis. Data were assessed by means of analysis of variance and paired t-tests. A p value of $\leq 0.05$ (two-tailed) was statistically significant.

Results Higher levels of antecedent hypoglycemia in the nocturnal hours were associated with greater time spent in next-day hypoglycemia overall $(p=0.003)$ and during exercise $(p=0.019)$. Occurrence of nocturnal hypoglycemia was associated with over three times the risk of next-day hypoglycemia $(p<0.001)$ and a twofold risk of low glucose during cycling $(p<0.001)$. Moreover, there was trend for a greater amount of time spent in mild hypoglycemia during the night compared with daytime hours $(p=0.080)$.

Conclusion The higher prevalence of nocturnal hypoglycemia was associated with an increased risk of next-day hypoglycemia, which extended to cycle training sessions. These data highlight the potential need for additional prebed carbohydrates and/or insulin dose reduction strategies around exercise training in professional cyclists with T1D.

Trial registration number DRKS00019923.

\section{INTRODUCTION}

Public health, clinical consensus and diabetes organizations advocate regular physical exercise as an important non-pharmacological

\section{Significance of this study}

What is already known about this subject?

- Although the physiological needs and/or demands of endurance exercise events have been documented within the literature, we know less about the realtime glycemic responses to performance and the consequential impact they may have on postexercise and nocturnal glucose trends in professional athletes with type 1 diabetes.

What are the new findings?

- This study demonstrates a higher prevalence of nocturnal hypoglycemia in athletes undertaking daily, strenuous exercise sessions as part of a 9-day training block.

- Occurrence of night-time hypoglycemia was associated with over three times the risk of next-day hypoglycemia and a twofold risk of low glucose during cycling.

How might these results change the focus of research or clinical practice?

- These findings highlight the need for additional prebed carbohydrates and/or insulin dose reduction strategies around physical exercise training so as to minimize potential aberrations in glucose throughout the nocturnal period.

- The data collected as part of this study helped to provide a foundation for the development of individualized nutritional, physiological and therapeutic strategies that may assist in improving exercise performance parameters through glycemic optimization in elite cyclists with type 1 diabetes.

therapy for people with type 1 diabetes (T1D). Current recommendations suggest adults attain at least 150 min per week of moderate-to-vigorous intensity activity and muscle strengthening exercises for maintenance of general health. ${ }^{1}$ Yet a number of individuals with T1D go well beyond these 
minimum guidelines. Indeed, within the current research literature base there exist several examples of extreme exercise completion in people with T1D, including half marathons $\left(21.1 \mathrm{~km}^{2}\right)$, marathons $\left(42.2 \mathrm{~km}^{3-6}\right)$, ultramarathons $\left(\sim 133 \mathrm{~km}^{7}\right)$, mountain ultramarathons $\left(82 \mathrm{~km}^{8}\right)$, relay ultramarathons $(65-84.5 \mathrm{~km}$ per athlete over 3 days $\left.^{9}\right)$, multiday marathon walks (42 $\mathrm{km}$ each day for 5 days $\left.{ }^{10}\right)$, Ironman events $(3.8 \mathrm{~km}$ swim, $180 \mathrm{~km}$ cycle, $42.2 \mathrm{~km} \mathrm{run}{ }^{11}$ ), Ultraman (3-day, multistage ultraendurance triathlons: $10 \mathrm{~km}$ swim, $144.8 \mathrm{~km}$ bike (day 1), $275.4 \mathrm{~km}$ bike (day 2 ), and $84.4 \mathrm{~km}$ run $(\text { day } 3)^{12}$ ), ultramarathon $\left(161 \mathrm{~km}\right.$ cycle and $\left.161 \mathrm{~km} \mathrm{run}{ }^{13}\right)$, multiday cycling events (15-day, $2300 \mathrm{~km} \mathrm{cycling}{ }^{14}$ ) and crosscountry ski events $\left(75 \mathrm{~km}\right.$ over $7+$ hours $\left.{ }^{15}\right)$. However, in such extreme exercises, frequent blood glucose monitoring is advised to minimize dysglycemia and assure safe participation. Notably, endurance athletes with T1D report a greater occurrence of hypoglycemia compared with their non-endurance sporting counterparts. ${ }^{16}$ As such, these athletes often require greater diligence to glucose management strategies that emphasize nutritional intake and insulin adjustment. Collectively, the complexity of sport and its characteristics, alongside the pathological heterogeneity of T1D, may explain the lack of athlete adherence to conventional glucose management recommendations around competitive exercise. ${ }^{17}$ Furthermore, the discomfort associated with frequent blood sampling during exercise may potentially occlude the true extent of exercise-induced dysglycemia. Hence, technological advances in continuous glucose monitoring (CGM) systems that enable automated glucose sensing from the interstitial compartment constitute convenient therapeutic aids that reduce the drawbacks of self-blood glucose monitoring during exercise. Indeed, integration of these devices during prolonged endurance exercise has proven successful in assisting glucose management via early identification of aberrations in glucose. ${ }^{5710121418} \mathrm{~A}$ recent international consensus statement has advocated clinical thresholds that stratify glycemia into distinct target ranges, ${ }^{19}$ that is, time spent (\%) below range (level 2 (L2): $<54 \mathrm{mg} / \mathrm{dL}$; level 1 (L1): $54-69 \mathrm{mg} / \mathrm{dL}$ ), time in range (TIR; $70-180 \mathrm{mg} / \mathrm{dL}$ ) and time above range (TAR; L1: $181-250 \mathrm{mg} / \mathrm{dL}$; L2: $>250 \mathrm{mg} / \mathrm{dL}$ ). These data can be mapped against insulin administration and mealtime feeding to help inform individualized treatment decisions and facilitate glycemic control. ${ }^{20}$ However, we know little about the suitability and relevance of these thresholds for professional athletes undergoing daily bouts of prolonged and strenuous exercise. Intriguingly, although the physiological needs and/or demands of these events have been documented within the literature, ${ }^{2} 1021$ we know less about the real-time glycemic responses to their participation and the consequential impact they may have on postexercise and nocturnal glucose trends. Despite the challenges of controlling glycemia in active people with T1D, elite cyclists like those in Team Novo Nordisk demonstrate that high-end athletic performance in world-class Union Cycliste Internationale cycle events

\begin{tabular}{|c|c|}
\hline Characteristics & Mean \pm SD \\
\hline Age (years) & $27 \pm 4$ \\
\hline Duration since diagnosis (years) & $11 \pm 5$ \\
\hline Height $(\mathrm{m})$ & $1.76 \pm 0.07$ \\
\hline Body mass (kg) & $67 \pm 6$ \\
\hline $\mathrm{BMI}\left(\mathrm{kg} / \mathrm{m}^{2}\right)$ & $22 \pm 1$ \\
\hline $\mathrm{HbA}_{1 \mathrm{c}}(\%)$ & $6.8 \pm 0.6$ \\
\hline $\mathrm{HbA}_{1 \mathrm{c}}(\mathrm{mmol} / \mathrm{mol})$ & $50.3 \pm 6.2$ \\
\hline $\mathrm{Hb}(\mathrm{g} / \mathrm{dL})$ & $150 \pm 70$ \\
\hline HCt (\%) & $42.2 \pm 1.6$ \\
\hline $\mathrm{HR}_{\max }(\mathrm{bpm})$ & $189 \pm 10$ \\
\hline$P_{\max }(W)$ & $395 \pm 46$ \\
\hline$\dot{\mathrm{V}} \mathrm{O}_{2 \max }(\mathrm{L} / \mathrm{min})$ & $4.9 \pm 0.4$ \\
\hline$\dot{\mathrm{V}} \mathrm{O}_{2 \max }\left(\mathrm{mL} \mathrm{O}_{2} / \mathrm{kg} / \mathrm{min}\right)$ & $73.1 \pm 3.8$ \\
\hline$\dot{\mathrm{V}}_{\mathrm{E} \max }(\mathrm{L} / \mathrm{min})$ & $177 \pm 25$ \\
\hline
\end{tabular}

Cardiopulmonary responses to incremental cycle test $(n=15$, mean \pm SD).

$\mathrm{BMI}$, body mass index; bpm, beats per minute; $\mathrm{Hb}$, hemoglobin; $\mathrm{HbA}_{1 \mathrm{c}}$, glycated hemoglobin; $\mathrm{HCt}$, hematocrit; $\mathrm{HR}_{\max }$, maximum heart rate; $\mathrm{P}_{\max }$, maximum power; $\mathrm{V}_{\mathrm{Emax}}$, ventilatory maximum; $\mathrm{VO} 2_{\text {max }}$, maximum rate of oxygen consumption.

is possible. This presents a novel window to systematically observe CGM-derived glycemic patterns of athletes with T1D undergoing prolonged, strenuous exercise sessions as part of an intense preseason training camp.

\section{Aim}

This prospective observational study sought to establish the glycemic, physiological and dietary demands of strenuous exercise training as part of a 9-day performance camp in a professional cycling team with T1D.

\section{MATERIALS AND METHODS \\ Study design}

This was an observational study.

\section{Participant characteristics}

Sixteen male cyclists with T1D from one professional cycling team volunteered to participate in this research study. All participants were provided with a full description of the study and signed an informed consent form prior to the start of any testing. The anthropometric and diabetes characteristics of all 16 participants are presented in table 1 . The physiological responses to the cardiopulmonary exercise (CPX) testing to volitional exhaustion are also detailed in table 1 . One cyclist was withdrawn from this test due to health issues.

\section{Participants' insulin regimen}

All riders were on a stable multiple daily dose regimen consisting of a range of rapid-acting/short-lasting 
and long-lasting insulin (bolus: $\mathrm{n}=6$ Fiasp, $\mathrm{n}=9$ NovoRapid, $n=1$ Apidra; basal: $n=10$ Lantus, $n=4$ Levemir, $\mathrm{n}=2$ Toujeo). Of the 16 riders, 13 took basal insulin in the evening while 3 riders were on a bidaily basal regimen. Cyclists' self-reported total insulin doses ranged between $24 \pm 14$ (minimum) and 28 \pm 15 (maximum) IU daily, consisting of a bolus of $11 \pm 4$ (minimum) to $12 \pm 4$ (maximum) IU daily, and basal of $13 \pm 10$ (minimum) to $16 \pm 12$ (maximum) IU daily.

\section{Cycle training regimen}

Riders performed eight training rides over 9 days lasting between 2 and 6 hours, traversing $56-183 \mathrm{~km} /$ day at $60 \%-75 \%$ maximum heart rate (HR), with 1 day dedicated to CPX testing (day 6). Participants performed all race stages on an individual time-trial basis with a mobile power meter (Pioneer, USA) and with a cycle computer (Wahoo, Wahoo Fitness, USA) mounted on their bike which allowed the monitoring, with a frequency of $1 \mathrm{~Hz}$, of power output $(\mathrm{W})$, cadence (revolutions per minute $(\mathrm{rpm}))$, temperature $\left({ }^{\circ} \mathrm{C}\right)$, speed $(\mathrm{km} /$ hour$)$, elevation $(\mathrm{m})$, grade $(\%)$ and daily racing regimen (ie, distance $(\mathrm{km})$, duration (hours), elevation gain $(\mathrm{m})$, energy expenditure $(\mathrm{kcal})$ ). Riders were instructed to perform zero-offset procedures prior to each training session according to manufacturers' instruction. HR was measured during every race using a portable chest strap (Garmin, USA). Cycle training metrics (time, speed, power, gradient, temperature, HR) were logged using Elemnt headset devices (Wahoo GPS cycle units) for later uploading via the Training Peaks computerized cloud-based package (Training Peaks, USA). A detailed overview of training-based metrics can be found in online supplementary file 1.2.

\section{Cardiopulmonary cycle exercise testing}

On day 6 of the training camp, cyclists performed an incremental CPX test on their personal bicycle (Colnago C60) attached to a cycle trainer (KICKR, Wahoo, USA). After a standardized warm-up phase, participants began testing at a fixed rate of $100 \mathrm{~W}$ with consequent workload increase of $10 \mathrm{~W}$ (Ergometer (ERG) mode) every minute until volitional exhaustion. Volitional exhaustion was defined as an inability to maintain a cadence $\geq 50 \mathrm{rpm}$ for $5 \mathrm{~s}$. During exercise, pulmonary gas exchange (MetaMax 3B; Cortex Biophysik, Leipzig, Germany) and HR (s810i, Polar Electro, Finland) were recorded continuously and subsequently averaged every $5 \mathrm{~s}$. Ratings of perceived exertion (Borg Scale ${ }^{22}$ ) and earlobe capillary blood lactate and glucose sampling (Biosen C-Line, EKF Diagnostics, Germany) were performed at rest and after each exercise stage.

\section{Continuous glucose monitoring}

Riders were provided with unblinded subcutaneous glucose monitoring systems (Dexcom G6, USA) for the duration of the study. A self-inserted subcutaneous glucose sensor was wirelessly connected to a glucose reader (Dexcom, USA). The water-resistant sensor was factory-calibrated with a shelf-life of 10 days. Data were downloaded for later export and analysis.

\section{Nutritional tracking and macronutrient reporting}

Over the 9-day training camp, a registered dietitian and team physician provided daily printed dietary plans for each meal. Each structured meal plan included a list of available food items and serving suggestion based on bodyweight. Food scales were provided at each meal sitting and riders were encouraged to use them to match meal plan amounts. Carbohydrate $(\mathrm{CHO}, \mathrm{g})$, protein $(\mathrm{g})$, fat $(\mathrm{g})$ and total energy ( $\mathrm{kcal})$ information was included in each document to guide individualized insulin doses. During exercise, dietary intake was recorded via the provision of individualized rider feed bags. Each bag contained a fixed amount of food items for which the nutrient composition was acquired directly from the product labels. Immediately after the ride, bags were returned, and the contents were analyzed by the research team. Quantities were then verified with each rider independently via social media text messages and verbal confirmation when necessary.

\section{Data analysis}

All statistical analyses were carried out using SPSS V.26.0 statistical software, and $\mathrm{p} \leq 0.05$ (two-tailed) was considered statistically significant. Unless stated otherwise, all data are presented as mean \pm SD. Relationships between variables were assessed using general linear regression. Between camp day differences were assessed by means of analysis of variance, while paired sampled t-tests were used to explore diurnal differences. A two-by-two crosstabulation analysis of nominally coded variables (hypoglycemia occurrence) was used to determine estimated risk ratios (ERR), with Fisher's exact test used to report $p$ values and Cramer's V scores to demonstrate the strength of relationship. CGM data were downloaded from the online Clarity platform for each rider over a 9-day period and grouped into day (06:00-23:59) or night (00:00-05:59) period. Per cent coverage was determined as the recorded number of data points divided by the maximum number of 5 min sample points within a time period. CGM from one rider was excluded for consent reasons. CGM data were stratified into time spent (\%) into predefined glycemic ranges in accordance with a recent international consensus statement. ${ }^{19}$ Data were grouped into L2 hypoglycemia $(<54 \mathrm{mg} / \mathrm{dL})$, L1 hypoglycemia ( $\geq 54$ to $\leq 69 \mathrm{mg} / \mathrm{dL}$ ), euglycemia ( $\geq 70$ to $\leq 180 \mathrm{mg}$ / dL), L1 hyperglycemia ( $\geq 181$ to $\leq 250 \mathrm{mg} / \mathrm{dL}$ ) and L2 hyperglycemia $(>250 \mathrm{mg} / \mathrm{dL})$.

\section{RESULTS}

\section{Overall energy intake and macronutrient composition}

A day-by-day breakdown of rider energy intake and macronutrient composition can be found in online supplementary file 1.1. On average, cyclists' diet comprised $63 \% \pm 8 \% \mathrm{CHO}, 15 \% \pm 3 \%$ protein and $22 \% \pm 8 \%$ fat. Inride 
Table 2 Inexercise energy intake across each day of the 9-day training camp

\begin{tabular}{|c|c|c|c|c|c|}
\hline \multicolumn{6}{|c|}{ Inexercise energy intake } \\
\hline Ride number & $\begin{array}{l}\text { Ride duration } \\
\text { (hours) }\end{array}$ & Energy (kcal/hour) & CHO (g/hour) & Fat (g/hour) & Protein (g/hour) \\
\hline Day 1 & $4.2 \pm 0.1$ & $163 \pm 93$ & $35 \pm 21$ & $2 \pm 1 \dagger$ & $2 \pm 1 \neq$ \\
\hline Day 2 & $5.5 \pm 1.4$ & $287 \pm 288^{*}$ & $60 \pm 65^{\star}$ & $5 \pm 4^{*} \dagger$ & $3 \pm 1$ \\
\hline Day 3 & $2.0 \pm 0.4$ & $90 \pm 102^{*}$ & $20 \pm 20^{*}$ & $1 \pm 3^{*}$ & $1 \pm 1 \neq$ \\
\hline Day 4 & $5.8 \pm 0.6$ & $222 \pm 60$ & $45 \pm 14$ & $4 \pm 1$ & $3 \pm 1$ \\
\hline Day 5 & $3.6 \pm 0.3$ & $264 \pm 111^{*}$ & $54 \pm 23$ & $4 \pm 2$ & $4 \pm 3 \ddagger$ \\
\hline Day 6 & CPX testing & & & & \\
\hline Day 7 & $3.3 \pm 1.2$ & $149 \pm 142$ & $30 \pm 25$ & $3 \pm 4$ & $2 \pm 2 \ddagger$ \\
\hline Day 8 & $4.7 \pm 0.6$ & $238 \pm 79$ & $48 \pm 15$ & $4 \pm 2^{\star}$ & $3 \pm 2$ \\
\hline Day 9 & $5.9 \pm 0.2$ & $261 \pm 93^{\star}$ & $55 \pm 21^{*}$ & $4 \pm 2$ & $2 \pm 1$ \\
\hline Overall & $4.3 \pm 1.5$ & $209 \pm 149$ & $44 \pm 32$ & $3 \pm 3$ & $2 \pm 2$ \\
\hline$P$ value & $<0.001$ & 0.002 & 0.002 & 0.004 & $<0.001$ \\
\hline
\end{tabular}

Dietary data were not collected on day 6 due to CPX testing.

Data are presented as mean $\pm \mathrm{SD}$ and expressed as intake per hour per kilogram of body mass. $\mathrm{N}=16$.

${ }^{*} \mathrm{P} \leq 0.05$ between day 3 and all other identified trials.

$\dagger P \leq 0.05$ between day 2 and all other identified trials.

$\ddagger \mathrm{P} \leq 0.05$ between day 5 and all other identified trials.

$\mathrm{CHO}$, carbohydrate; $\mathrm{CPX}$, cardiopulmonary exercise.

nutrient consumption ranged from $12 \%$ to $25 \%$ of the total daily energy intake. Considerably more calories were consumed on day 9 versus all other days ( $\leq \leq 0.001$; $k c a l)$. Similarly, more $\mathrm{CHO}$ were consumed on day 9 compared with all other days bar day 2 ( $\mathrm{p} \leq 0.009$; $\mathrm{CHO} *)$. However, day 2 did differ from days $1(\mathrm{p}=0.004), 3(\mathrm{p}=0.012)$ and $7(\mathrm{p}<0.001 ; \mathrm{CHO})$. Both total energy $(\beta=0.348, \mathrm{p}<0.001)$ and CHO $(\beta=0.186, p=0.027)$ intake increased linearly alongside camp duration. Protein intake was lowest on the first day of training camp and differed from the later 3 days of camp $(\mathrm{p}<0.001$; Pro $)$. With the exception of day 2 (which differed from days 1, 3, 4, 5 and 6; Pro), protein intake also increased with camp duration $(\beta=0.375$, $\mathrm{p}<0.001$ ). Although the same was true for fat intake (day 1 lowest value compared with days 2, 3, 5, 7, 8 and 9; $\mathrm{p} \leq 0.008$; fat), fat consumption was lower on day 6 (CPX testing with no formal training ride) compared with most other days (days 2, 3, 5, 7 and 8; $\mathrm{p} \leq 0.003$; fat) and failed to demonstrate significant signs of a linear relationship with camp duration $(\beta=0.106, p=0.213)$.

\section{Inexercise energy intake and macronutrient composition}

A descriptive table of energy intake and macronutrient composition during exercise is shown in table 2.

Analysis of mean nutrition data over the training camp revealed cyclists' energy consumption was $209 \pm 149 \mathrm{kcal} /$ hour, consisting of $44 \pm 32 \mathrm{~g} /$ hour $(77 \%)$ CHO, $3 \pm 3 \mathrm{~g} /$ hour $(13 \%)$ fat, and $2 \pm 1 \mathrm{~g} /$ hour $(10 \%)$ protein. Dayby-day analysis revealed significantly more energy was consumed on day 3 versus days $2(\mathrm{p}=0.005), 5 \quad(\mathrm{p}=0.024)$ and $9(\mathrm{p}=0.036$; kcal). Further macronutrient analysis indicated that this calorie deficit was accounted for by lesser amounts of $\mathrm{CHO}$ on day 3 versus both days $2(p=0.010)$ and $9(p=0.049 ; \mathrm{CHO})$. Similarly, less fat was consumed on day 3 versus days $2(p=0.011)$ and 8 ( $p=0.023$; fat), but also on day 2 versus day $1 \quad(p=0.050$; fat). Finally, more protein was consumed on day 5 versus days $1(\mathrm{p}=0.014), 3(\mathrm{p}<0.001)$ and $7(\mathrm{p}=0.001$; Pro $)$.

Figure 1 illustrates the relationships between exercise length and inride energy intake. Cycle duration was related to total energy $(\beta=0.679, p<0.001)$, CHO $(\beta=0.660, p<0.001)$, fat $(\beta=0.601, p<0.001)$ and protein intake $(\beta=0.497, \mathrm{p}<0.001)$.

However, no macronutrient explained the variance in inride interstitial glucose (iG) concentration. Similarly, the time spent in each glycemic range during the nocturnal hours that preceded next-day cycle sessions had no impact on inride dietary intake.

\section{Exercise physiological responses to cycle training sessions}

The physical and physiological responses to cycle training sessions are reported in online supplementary file 1.2 and table 2. Cycle distance ranged from 56 to $183 \mathrm{~km} /$ day, with a duration of $4.3 \pm 1.4$ hours per session. The mean power output was approximately $50 \%$ of the peak aerobic power obtained during the cardiopulmonary cycle test. The maximum power elicited during cycle training sessions was twice that of the peak aerobic power during the CPX test. The mean cycle HR $(131 \pm 11$ beats per minute (bpm)) was $70 \%$ of the maximum values $(189 \pm 10 \mathrm{bpm})$. The peak HR obtained during cycle training was $91 \%$ of that obtained at the end of the cardiopulmonary cycle test. Cycle training sessions consisted of most time spent in HR zones 1-3 (please refer to online supplementary file 1.2). 
A)

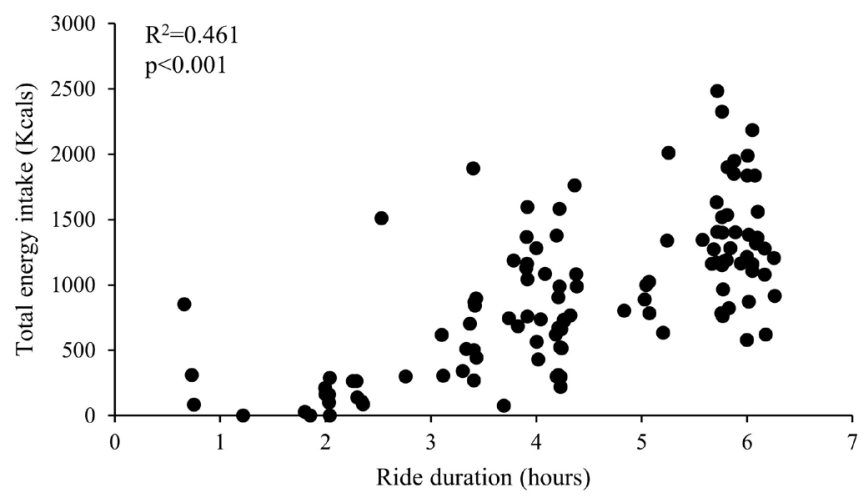

C)

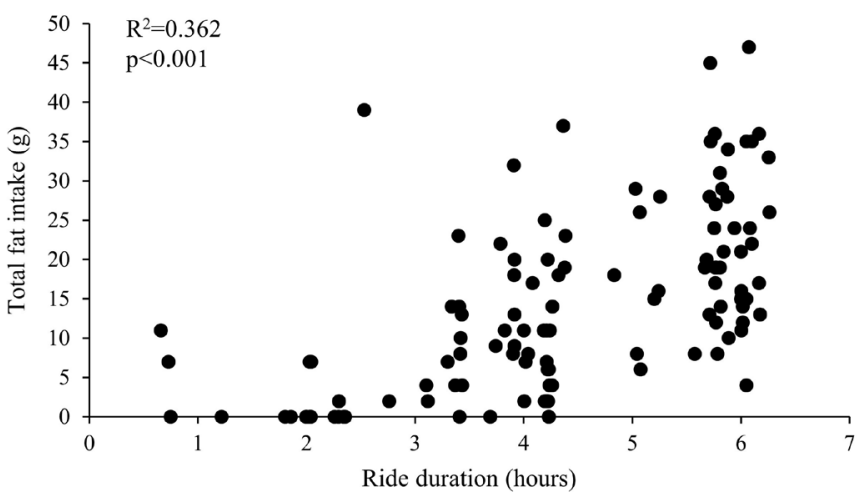

B)

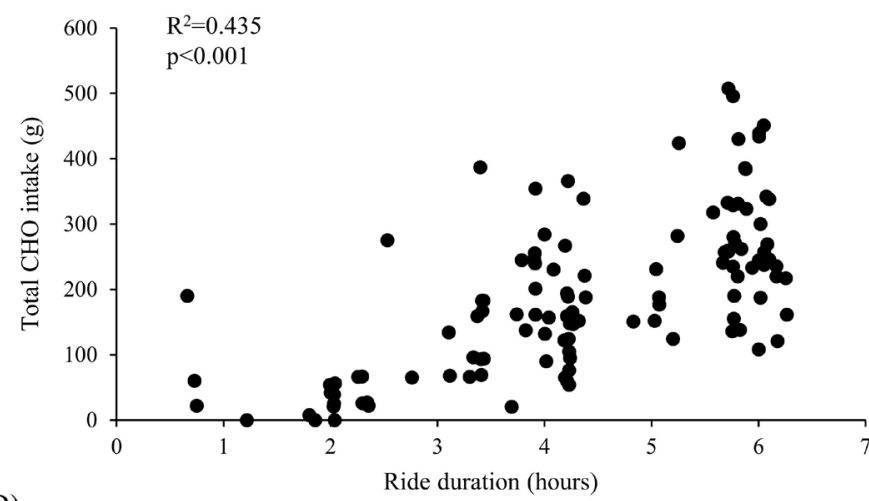

D)

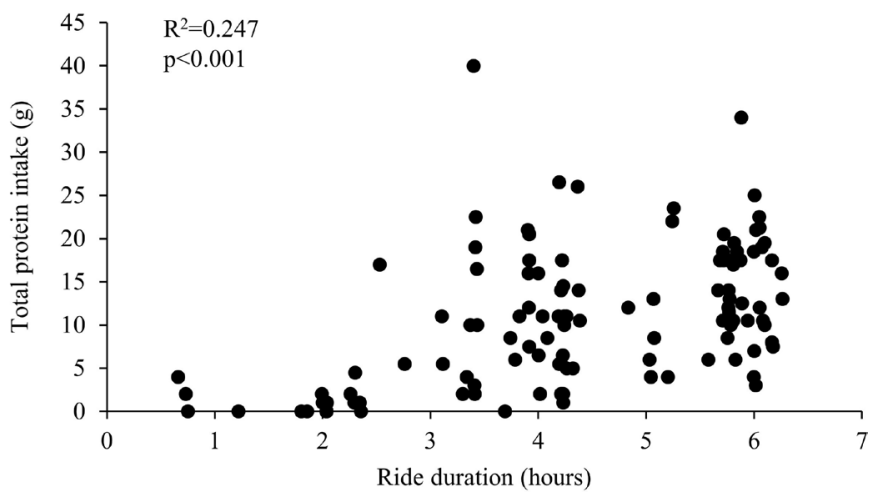

Figure 1 Cycle duration as it relates to total energy $(A)$, carbohydrate $(C H O)(B)$, fat $(C)$ and protein $(D)$ intake.

\section{Glycemic data}

Overall glycemia during training camp

Continuous iG profiles from the 24 hours over 9 days revealed that riders spent $76 \%$ of time in euglycemia, $18 \%$ of time in hyperglycemia (L1: 15; L2: $3 \%$ ) and 6\% of time in hypoglycemia (L1: 4; L2: $2 \%$ ). CGM was active $80 \% \pm 13 \%$ of time over the 9 days of data collection and did not differ between daytime and night-time periods (day $78 \% \pm 17 \%$ vs night $82 \% \pm 10 \%, \mathrm{p}=0.424$ ).

\section{Day-by-day glycemic variance during training camp}

A graphical illustration of the mean $\mathrm{iG}$ for each day and night and overall can be found in online supplementary file 1.3. There was no difference between camp days in either the daytime $(p=0.263)$ or night-time $(p=0.497)$ mean glucose concentrations. The time spent in different glycemic ranges stratified into day (06:00-23:59), night (00:00-05:59) and exercise-only time periods are presented in figure 2 .

During the day-time periods, there was no difference in the amount of time spent in hypoglycemia ( $\mathrm{L} 2 ; \mathrm{p}=0.65$, $\mathrm{L} 1 ; \mathrm{p}=0.86$ ), euglycemia $(\mathrm{p}=0.93)$ or L1 hyperglycemia $(p=0.96)$. However, camp days differed in the amount of time spent in L2 hyperglycemia $(p=0.01)$. Although pairwise comparisons failed to identify the source of significance, it appeared to be driven by a greater amount of time spent in L2 hyperglycemia on day 2 versus day 7 (day 2: $1 \%$ vs day $7: 5 \%, \mathrm{p}=0.084)$.
There was no difference between nights in the amount of time spent in either hypoglycemia ( $\mathrm{L} 2 ; \mathrm{p}=0.88$, $\mathrm{L} 1 ; \mathrm{p}=0.73)$ or L2 hyperglycemia $(\mathrm{p}=0.89)$. However, nocturnal periods differed in the amount of time spent in both euglycemia $(p=0.05)$ and L1 hyperglycemia $(p=0.05)$. Although pairwise analysis failed to exact significance, the greatest difference was between night 6 and night 9 (euglycemia night 6: $90 \%$ vs night 9: $59 \%$, $\mathrm{p}=0.215$; L1 hyperglycemia night $6: 4 \%$ vs night $9: 27 \%$, $\mathrm{p}=0.233)$.

\section{Day versus night iG patterns}

Overall, there was no difference between the mean day $\mathrm{iG}$ compared with night (day $138 \pm 25 \mathrm{mg} / \mathrm{dL}$ vs night $135 \pm 44 \mathrm{mg} / \mathrm{dL}, \mathrm{p}=0.421)$. The $\mathrm{SD}$ of $\mathrm{iG}$ was greater during daytime than night-time hours (day $43 \pm 16 \mathrm{mg} / \mathrm{dL}$ vs night $25 \pm 20 \mathrm{mg} / \mathrm{dL}, \mathrm{p}<0.001)$. Coefficient of variation $(\%)$ in data was also higher during the daytime period (day $31 \% \pm 10 \%$ vs night $19 \% \pm 13 \%, \mathrm{p}<0.001$ ). Although the average peak glucose concentration was higher during the day versus the night hours (day $211 \pm 58 \mathrm{mg}$ / $\mathrm{dL}$ vs night $178 \pm 61 \mathrm{mg} / \mathrm{dL}, \mathrm{p}<0.001)$, the minimum value was similar (day $89 \pm 29 \mathrm{mg} / \mathrm{dLvs}$ night $94 \pm 37 \mathrm{mg} / \mathrm{dL}$, $\mathrm{p}=0.095)$.

When separated into daytime and night-time periods, there was no difference in the time spent below target (L1 and L2) during the nocturnal hours (night $8 \%$ vs day $6 \%, \mathrm{p}=0.155)$. While there were also no differences when data were stratified into L1 and L2 ranges, there was a 


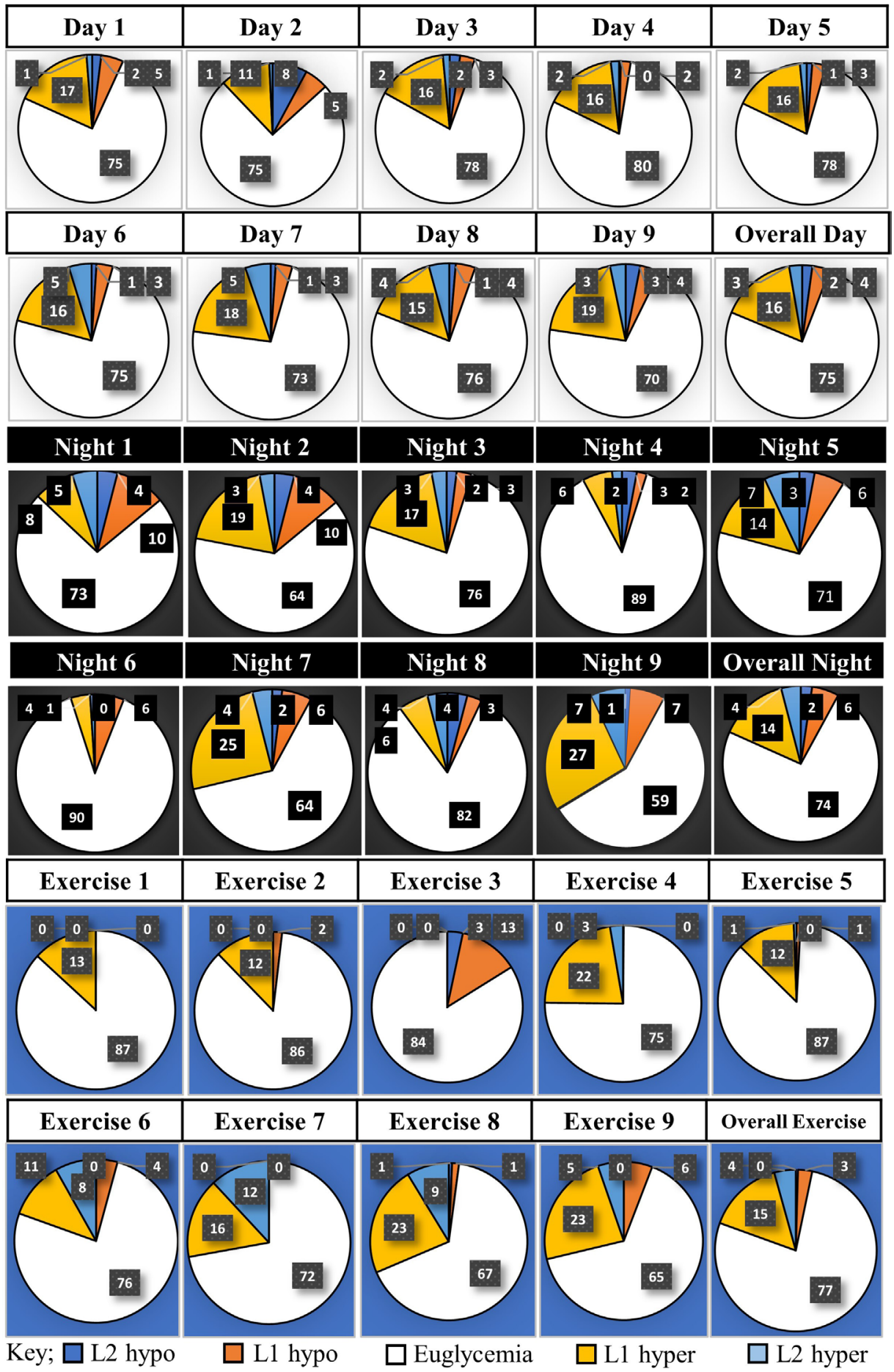

Figure 2 Time spent in different glycemic ranges split into day (06:00-23:59), night (00:00-05:59) and exercise-only time periods $(\%$, mean $\pm S D, n=15)$. $P$ values represent the difference between camp days in time spent in each glycemic threshold. Dark blue segment on pie chart represents time spent (\%) in level 2 hypoglycemia $(<54 \mathrm{mg} / \mathrm{dL})$. Orange segment on pie chart represents time spent (\%) in L1 hypoglycemia $(\geq 54$ to $\leq 69 \mathrm{mg} / \mathrm{dL}$ ). White segment on pie chart represents time spent $(\%)$ in euglycemia ( $\geq 70$ to $\leq 180 \mathrm{mg} / \mathrm{dL}$ ). Yellow segment on pie chart represents time spent (\%) in L1 hyperglycemia $(\geq 181$ to $\leq 250 \mathrm{mg} /$ $\mathrm{dL})$. Light blue segment on pie chart represents time spent (\%) in L2 hyperglycemia ( $>250 \mathrm{mg} / \mathrm{dL}$ ). Eu, euglycemia; Hyper, hyperglycemia; Hypo, hypoglycemia; L1, level 1; L2, level 2.

trend for increased time spent in L1 hypoglycemia during the night-time (L1 night $5.6 \% \pm 12.8 \%$ vs day $3.6 \% \pm 5.2 \%$, $\mathrm{p}=0.080$; L2 night $2.4 \% \pm 7.4 \%$ vs day $2.0 \% \pm 9.9 \%$, $\mathrm{p}=0.666$ ). There were no differences between daytime and nighttime spent in euglycemia (night $74.3 \% \pm 29.3 \%$ vs day
$75.7 \% \pm 17.6 \%, \mathrm{p}=0.602)$ and in L1 (night $13.6 \% \pm 21.7 \%$ vs day $15.9 \% \pm 14.2 \%, \mathrm{p}=0.260$ ) or L2 (night $4.1 \% \pm 11.6 \%$ vs day $2.8 \% \pm 4.2 \%, \mathrm{p}=0.284$ ) hyperglycemia.

A greater amount of time spent in nocturnal hypoglycemia was related to a greater amount of time spent 
below target range the following day $(\beta=0.265, \mathrm{p}=0.003)$. Furthermore, the occurrence of nocturnal hypoglycemia was associated with a 3.6-fold increase in risk of experiencing next-day hypoglycemia (ERR 3.641 (95\% CI 1.589 to 8.345 ), $\mathrm{p}<0.001$, Cramer's V=0.360).

\section{Glycemic responses to cycle training sessions}

The time spent in euglycemia ranged from $69.4 \%$ to $85.3 \%$ across different training days. The mean $\mathrm{iG}$ was $140 \pm 42 \mathrm{mg} / \mathrm{dL}$, ranging from the lowest recorded value of $46 \mathrm{mg} / \mathrm{dL}$ to a peak concentration of $331 \mathrm{mg} / \mathrm{dL}$. The mean $\mathrm{iG}$ was negatively correlated to the occurrence of L2 $(\mathrm{r}=-0.271, \mathrm{p}=0.010)$ and L1 $(\mathrm{r}=-0.410, \mathrm{p}<0.001)$ hypoglycemia, and positively correlated to the occurrence of both L1 $(\mathrm{r}=0.769, \mathrm{p}<0.001)$ and L2 hyperglycemia $(\mathrm{r}=0.665$, $\mathrm{p}<0.001)$. There was no difference between rides in the amount of time spent in either eu- $(\mathrm{p}=0.60)$ or hyperglycemia ( $\mathrm{L} 1 ; \mathrm{p}=0.51, \mathrm{~L} 2 ; \mathrm{p}=0.27)$. There was a significant difference between cycle sessions in the amount of time spent in both L2 ( $\mathrm{p}=0.04)$ and L1 $(\mathrm{p}=0.03)$ hypoglycemia over the training camp. Further analysis identified that day 3 was associated with more time spent in L2 hypoglycemia than days $4(\mathrm{p}=0.060), 5(\mathrm{p}=0.035)$ and $6(\mathrm{p}=0.074)$. Similarly, day 3 had higher levels of L1 hypoglycemia than days $4(\mathrm{p}=0.048), 5(\mathrm{p}=0.050)$ and 7 $(\mathrm{p}=0.070)$. A greater time spent in hypoglycemia during the night-time period was associated with a higher prevalence of next-day hypoglycemia during cycling $(\beta=0.252$, $\mathrm{p}=0.019$ ). Nocturnal hypoglycemia was associated with a 1.8-fold increase in the risk of next-day inride hypoglycemia (ERR 1.797 (95\% CI 1.22 to 2.634), p<0.001, Cramer's V=0.484).

\section{DISCUSSION}

This study was the first to establish the glycemic, physiological and dietary demands of strenuous exercise training as part of a 9-day performance camp in a professional cycling team with T1D. Cyclists with T1D maintained a large proportion of time in a euglycemic range and fell within clinical recommendations. However, we have demonstrated that antecedent hypoglycemia in the nocturnal hours that preceded next-day cycling was associated with over three times the risk of next-day hypoglycemia and a 1.8-fold increase in the risk of experiencing hypoglycemia while cycling.

\section{4-hour glycemia}

Twenty-four-hour glycemic data generated over the 9-day training camp demonstrated revealing insights of professional cyclists with T1D engaged in intense exercise. Clinical recommendations endorsed by several international diabetes associations, foundations and societies established adult iG targets to attain $<5 \%$ of TIR at L2 hyperglycemia, $<25 \% \mathrm{~L} 1$ hyperglycemia, $>70 \% \mathrm{TIR},<4 \% \mathrm{~L} 1$ hypoglycemia and $<1 \% \mathrm{~L} 2$ hypoglycemia, respectively. ${ }^{19}$ Our data demonstrate cyclists spent $3 \%$ of time with L2 hyperglycemia, $15 \%$ with L1 hyperglycemia, $76 \%$ TIR,
$4 \% \mathrm{~L} 1$ hypoglycemia and 2\% L2 hypoglycemia, respectively. These data inform several discussion points. The time spent in euglycemia $(76 \%)$ was categorized as 'very good' against current clinical recommendations ${ }^{19}$ and commendable for a team of cyclists riding on average 4.3 hours and consuming $~ 5000 \mathrm{kcal}$ each day. Such intense demands of cycling (in which the rate of glucose combustion is markedly increased over the rest values) and large macronutrient intake may account for the large coefficient of variation in riders' data $(36 \%-38 \%$ coefficient of variation). A lower time spent in hyperglycemia (L1 and L2: 18\%) is admirable and falls within the $<30 \%$ value recommended for individuals with diabetes. ${ }^{19}$ However, although time spent in L1 hypoglycemia was acceptable, the amount spent in L2 hypoglycemia was twice that recommended by clinical guidelines (2\% vs $1 \%$ ). Tempering this $1 \%$ higher rate of L2 hypoglycemia may be a challenge given the inherent physical demands of professional cycling, but technological advancements around monitoring of glucose, insulin and food intake may aid in the implementation of more refined, rapid and individualized strategies that collectively contribute to a reduction in this value.

Our observations revealed a tendency for greater nocturnal hypoglycemia compared with daytime. That the riders were in a daily postexercise insulin-sensitized state, administered basal insulin in the evening, and may not have eaten for 2-3 hours before bed may create an environment where nocturnal hypoglycemia is more frequent. Indeed, an interesting observation was greater nocturnal hypoglycemia in the first 2 days of training and might suggest an early maladaptive response to the 4.2-hour and 5.5-hour cycle rides. More attention to managing this occurrence might focus on late prebed feeding or adjustments in insulin administration strategies. ${ }^{23}$ A limitation of our study was the inability to monitor cyclists' insulin administration strategies, but reductions in basal and/or bolus insulin have been demonstrated to improve postexercise and glycemia observationally and in laboratory-controlled studies. ${ }^{2} 381011151824$ It should be noted that rider monitoring is difficult in the early morning hours when asleep, and although glycemic threshold alarms are possible on CGM devices alarm threshold settings are highly individualized and balanced between being too high to facilitate sleep or too low to prevent a hypoglycemic event from occurring.

\section{Inride glycemia and nutritional intake}

Despite the long duration of most of the cycle rides, the mean iG was euglycemic during each cycle ride. The mean iG during cycling was negatively correlated to the occurrence of L2 hypoglycemia $(r=-0.227, p=0.043)$ and positively correlated to the occurrence of L1 ( $\mathrm{r}=0.234$, $\mathrm{p}=0.037$ ) hyperglycemia, thus presenting an indicator of the importance of supporting glycemia in the upper boundaries of 'euglycemia' during cycling. These data might suggest a case for additional $\mathrm{CHO}$ to support glucose concentrations within the higher end of the 
euglycemic range, without compromising time spent in hyperglycemia but with the added benefit of available energy for combustion to power cycling performance. We also demonstrated that antecedent hypoglycemia in the nocturnal hours that precede next-day cycle exercise was associated with a greater risk of inexercise hypoglycemia. It is well known that antecedent hypoglycemia influences the counter-regulatory hormone response to exercise. ${ }^{25}{ }^{26}$ Additionally, subsequent episodes of hypoglycemia can exacerbate the blunted responses to latent hypoglycemia and ultimately further perpetuate the likelihood of repeat hypoglycemia. ${ }^{27}$

Inride macronutrient analysis revealed high relative CHO proportions $(77 \%)$, with fat $(13 \%)$ and protein $(10 \%)$, accounting for the remainder of dietary intake during rides. Cyclists consumed between 13\% and 25\% of their total daily energy intake on the bike, and this was dependent on ride duration. However, when the rate of $\mathrm{CHO}$ intake (CHO g/hour) was grouped according to the length of cycle sessions, we found cyclists consumed CHO at a rate of $20-30 \mathrm{~g} /$ hour for a ride of 2-3 hours, 35-53 g CHO/hour between 3.5-hour and 4.5-hour cycle, and $45-58 \mathrm{~g} \mathrm{CHO} /$ hour on rides lasting between 4.5 and 6.0 hours. This differs markedly from general recommendations for endurance athletes of $60 \mathrm{~g} / \mathrm{hour}$ for exercise lasting 2-3 hours and $90 \mathrm{~g}$ /hour for event duration $>3$ hours. ${ }^{28} 29$ Although whether or not these guidelines are realistic has recently been questioned, with research detailing that athletes often fail to attain these targets during long distance events. ${ }^{30} 31$ In our data, a possible explanation for the shortfall may be the tendency of riders to consume a large breakfast prior to cycling (estimated calorie intake during this meal ranged between 900 and $1700 \mathrm{kcal}$ and represented $\sim 25 \%$ of the total daily nutrient intake); CHO intake rate still appears low compared with recommendations for athletic individuals without diabetes. As iterated above, it is interesting to speculate on the potential for practicing greater $\mathrm{CHO}$ ingestion (of a low glycemic index) to benefit sprints or end of stage racing while optimizing glycemic management. Furthermore, these data provide an initial platform from which individualized dietary plans can be implemented to ensure adequate fuel provision at a rate that is not only dependent on the absolute exercise intensity, but also the duration of the event.

Finally, as most cyclists took evening basal Lantus or split Levemir alongside relatively small amounts of bolus insulin, riders may have had relatively low circulating insulin concentrations during cycling. From an exercise performance perspective, higher concentrations of circulating exogenous insulin during cycling, concomitant with a stronger counter-regulatory hormone response to the exercise stimulus, may facilitate an increase in localized intramuscular glucose uptake. Thus, although the cost of this in terms of variance in glycemia is not known, experimentation in pre-exercise and postexercise mealtime individualized insulin to $\mathrm{CHO}$ ratios may translate to improved exercise performance and/or recovery outcomes.

\section{CONCLUSIONS}

This study demonstrated that professional cyclists with T1D maintained a large proportion of time in a euglycemic range over a 9-day intensified cycle training period. However, there was a tendency for higher levels of nocturnal hypoglycemia, which led to an increased risk of next-day hypoglycemia and a consequential impact on glucose during cycling training sessions. The potential long-lasting, insulin-sensitizing effects of endurance cycling illustrates a need for intensive monitoring of riders and dynamic, individualized glycemic management strategies. These data provide a foundation for the development of individualized nutritional, physiological and therapeutic strategies that may assist in improving exercise performance through glycemic optimization in elite cyclists with T1D.

\section{Study strengths, limitations and future recommendations}

This study is the first to systematically detail the glycemic effects of strenuous cycle training as part of a performance training camp in professional cyclists with T1D. Access to a combination of power meter data, inride nutrition and CGM in 16 professional cyclists with T1D has enabled a growth in our understanding of the demands of exercise performance at a world-class level. Given our population cohort, a clear limitation was the lack of detailed information on exogenous insulin analog administration over the course of camp. It should also be noted that CGM data were collated over a 9-day timeframe and thus fall slightly below the 2-week period referenced for adequate coverage guidelines. Future research would benefit from investigating the potential glycemic implications of exogenous basal-bolus insulin dosing strategies around intense exercise training, so as to improve our understanding of the physiological, nutritional and therapeutic demands of elite performance in athletes with T1D.

\section{Author affiliations}

${ }^{1}$ Applied Sports, Technology, Exercise and Medicine, Swansea University, Swansea, UK

${ }^{2}$ Diabetes Research Group, Swansea University, Swansea, UK

${ }^{3}$ Cardiovascular Diabetology Research Group, Division of Endocrinology and Diabetology, Department of Internal Medicine, Medical University of Graz, Graz, Steiermark, Austria

${ }^{4}$ Research Institute for Sport and Exercise Science, Liverpool John Moores University, Liverpool, UK

${ }^{5}$ Department of Neurological and Movement Sciences, University of Verona, Verona, Veneto, Italy

${ }^{6}$ Team Novo Nordisk Professional Cycling Team, Atlanta, Georgia, USA

${ }^{7}$ Diablo Clinical Research Center, Concord, California, USA

${ }^{8}$ Diabetes, Endocrinology, Nutritional Medicine and Metabolism, Inselspital, Bern University Hospital, University of Bern, Bern, Switzerland

${ }^{9}$ University of Glasgow, Glasgow, UK

${ }^{10}$ Department of Medicine, Emory University, Atlanta, Georgia, USA

${ }^{11}$ Kinesiology and Health Science, York University, Toronto, Ontario, Canada

${ }^{12}$ Team Novo Nordisk Academic and Clinical Advisors, Team Novo Nordisk

Professional Cycling Team, Atlanta, Georgia, USA 
Acknowledgements The authors would like to thank the participants for their willingness to assist in data sharing and collection. They would also like to thank all staff members of Team Novo Nordisk for their invaluable contributions to data collection.

Contributors OMc, OM, MLE, RMB, SNS, FYF, MPC, CS, MF, BB, MCR, CH, PLL, and PS contributed to data collection. OMc, OM, MLE, RMB, SNS, and FYF were responsible for data interpretation and analysis. RMB, OMc, OM, and MLE wrote the manuscript. RMB wrote and secured funding for the study. All coauthors contributed to feedback and revisions for the final manuscript.

Funding This study was funded by Novo Nordisk UK as part of an ISS.

Disclaimer The funding agency had no role in either the design of the study, the collection or analysis of data, or the decision to publish the manuscript.

Competing interests None declared.

Patient consent for publication Not required.

Ethics approval Ethical approval was granted by the Swansea University Research Ethics Committee (Ethics Committee reference number: 2018-140) and conducted in accordance with the Declaration of Helsinki and the International Conference on Harmonisation Good Clinical Practice. All participants provided written informed consent prior to participation.

Provenance and peer review Not commissioned; externally peer reviewed.

Data availability statement All data relevant to the study are included in the article or uploaded as supplementary information.

Open access This is an open access article distributed in accordance with the Creative Commons Attribution Non Commercial (CC BY-NC 4.0) license, which permits others to distribute, remix, adapt, build upon this work non-commercially, and license their derivative works on different terms, provided the original work is properly cited, appropriate credit is given, any changes made indicated, and the use is non-commercial. See: http://creativecommons.org/licenses/by-nc/4.0/.

ORCID iDs

Olivia McCarthy http://orcid.org/0000-0001-6971-611X

Sam N Scott http://orcid.org/0000-0003-2342-9865

Christoph Stettler http://orcid.org/0000-0003-1691-6059

Othmar Moser http://orcid.org/0000-0002-1661-0685

\section{REFERENCES}

1 Colberg SR, Sigal RJ, Yardley JE, et al. Physical Activity/Exercise and diabetes: a position statement of the American diabetes association. Diabetes Care 2016;39:2065-79.

2 Murillo S, Brugnara L, Novials A. One year follow-up in a group of half-marathon runners with type-1 diabetes treated with insulin analogues. J Sports Med Phys Fitness 2010;50:506-10.

3 Hartvig Jensen T, Darre E, Holmich P, et al. Insulin-Dependent diabetes mellitus and marathon running. $\mathrm{Br} \mathrm{J}$ Sports Med 1987;21:51-2.

4 Grimm JJ, Muchnick S. Type I diabetes and marathon running Diabetes Care 1993;16:1624-5.

5 Cauza E, Hanusch-Enserer U, Strasser B, et al. Continuous glucose monitoring in diabetic long distance runners. Int J Sports Med 2005;26:774-80.

6 Graveling AJ, Frier BM. Risks of marathon running and hypoglycaemia in type 1 diabetes. Diabet Med 2010;27:585-8.

7 Knechtle B, Nikolaidis PT. [Ultramarathon with Type 1 Diabetes]. Praxis 2018;107:777-81.

8 Gawrecki A, Zozulinska-Ziolkiewicz D, Matejko B, et al. Safe completion of a TRAIL running Ultramarathon by four men with type 1 diabetes. Diabetes Technol Ther 2018;20:147-52.

9 Belli T, de Macedo DV, Scariot PPM, et al. Glycemic contro and muscle damage in 3 athletes with type 1 diabetes during a successful performance in a relay Ultramarathon: a case report. Wilderness Environ Med 2017:28:239-45.

10 van Dijk J-W, Eijsvogels TM, Nyakayiru J, et al. Glycemic control during consecutive days with prolonged walking exercise in individuals with type 1 diabetes mellitus. Diabetes Res Clin Pract 2016;117:74-81.

11 Boehncke S, Poettgen K, Maser-Gluth C, et al. Ausdauerleistungsfähigkeit von triathlon-athleten MIT typ-1-diabetes. Dtsch med Wochenschr 2009;134:677-82.

12 Bach CW, Baur DA, Hyder WS, et al. Blood glucose kinetics and physiological changes in a type 1 diabetic finisher of the Ultraman triathlon: a case study. Eur J Appl Physiol 2017;117:913-9.

13 Khodaee M, Riederer M, VanBaak K, et al. Ultraendurance athletes with type 1 diabetes: Leadville 100 experience. Wilderness Environ Med 2015;26:273-5.

14 Hill NE, Campbell C, Buchanan P, et al. Biochemical, physiological and psychological changes during endurance exercise in people with type 1 diabetes. J Diabetes Sci Technol 2017;11:529-36.

15 Sane T, Helve E, Pelkonen R, et al. The adjustment of diet and insulin dose during long-term endurance exercise in type 1 (insulindependent) diabetic men. Diabetologia 1988;31:35-40.

16 Ratjen I, Weber KS, Roden M, et al. Type 1 diabetes mellitus and exercise in competitive athletes. Exp Clin Endocrinol Diabetes 2015;123:419-22.

17 Devadoss M, Kennedy L, Herbold N. Endurance athletes and type 1 diabetes. Diabetes Educ 2011;37:193-207.

18 Yardley JE, Zaharieva DP, Jarvis C, et al. The "ups" and "downs" of a bike race in people with type 1 diabetes: dramatic differences in strategies and blood glucose responses in the Paris-to-Ancaster Spring Classic. Can J Diabetes 2015;39:105-10.

19 Battelino T, Danne T, Bergenstal RM, et al. Clinical targets for continuous glucose monitoring data interpretation: recommendations from the International consensus on time in range. Diabetes Care 2019;42:1593-603.

20 Danne T, Nimri R, Battelino T, et al. International consensus on use of continuous glucose monitoring. Diabetes Care 2017;40:1631-40.

21 Gawrecki A, Naskret D, Niedzwiecki P, et al. High-Intensity exercise in men with type 1 diabetes and mode of insulin therapy. Int J Sports Med 2017;38:329-35.

22 Borg GA. Psychophysical bases of perceived exertion. Med Sci Sports Exerc 1982;14:377-81

23 West DJ, Stephens JW, Bain SC, et al. A combined insulin reduction and carbohydrate feeding strategy $30 \mathrm{~min}$ before running best preserves blood glucose concentration after exercise through improved fuel oxidation in type 1 diabetes mellitus. J Sports Sci 2011;29:279-89.

24 Vlahek P, Car S, Ostroški I. Sweet $452 \mathrm{~km}$--a report on the first type 1 diabetes patient to finish Double Ironman, a 30-hour endurance triathlon race. Croat Med J 2013;54:306-7.

25 Galassetti P, Tate D, Neill RA, et al. Effect of antecedent hypoglycemia on counterregulatory responses to subsequent euglycemic exercise in type 1 diabetes. Diabetes 2003;52:1761-9.

26 Galassetti P, Tate D, Neill RA, et al. Effect of differing antecedent hypoglycemia on counterregulatory responses to exercise in type 1 diabetes. Am J Physiol Endocrinol Metab 2006;290:E1109-17.

27 Davis SN, Galassetti P, Wasserman DH, et al. Effects of antecedent hypoglycemia on subsequent counterregulatory responses to exercise. Diabetes 2000;49:73-81.

28 Jeukendrup AE. Nutrition for endurance sports: marathon, triathlon, and road cycling. J Sports Sci 2011;29:S91-9.

29 Thomas DT, Erdman KA, Burke LM. Position of the Academy of nutrition and dietetics, dietitians of Canada, and the American College of sports medicine: nutrition and athletic performance. $J$ Acad Nutr Diet 2016;116:501-28.

30 Cox GR, Snow RJ, Burke LM. Race-day carbohydrate intakes of elite triathletes contesting olympic-distance triathlon events. Int $J$ Sport Nutr Exerc Metab 2010;20:299-306.

31 Pfeiffer B, Stellingwerff T, Hodgson AB, et al. Nutritional intake and gastrointestinal problems during competitive endurance events. Med Sci Sports Exerc 2012;44:344-51. 